\title{
Improved Vegetation Profiles with GOCI Imagery Using Optimized BRDF Composite
}

\author{
Sang-il Kim, ${ }^{1}$ Do-Seob Ahn, ${ }^{1}$ Kyung-Soo Han, ${ }^{2}$ and Jong-Min Yeom ${ }^{3}$ \\ ${ }^{1}$ Electronics and Telecommunications Research Institute (ETRI), 218 Gajeongno, Yuseong-gu, Daejeon 305-700, Republic of Korea \\ ${ }^{2}$ Department of Geoinformatic Engineering, Pukyong National University, Daeyeon-3 Nam-Gu, Busan 608-737, Republic of Korea \\ ${ }^{3}$ Korea Aerospace Research Institute (KARI), 169-84 Gwahak-ro, Yuseong-gu, Daejeon 305-806, Republic of Korea
}

Correspondence should be addressed to Jong-Min Yeom; yeom.jongmin@gmail.com

Received 27 November 2015; Revised 30 December 2015; Accepted 31 January 2016

Academic Editor: Chiman Kwan

Copyright (C) 2016 Sang-il Kim et al. This is an open access article distributed under the Creative Commons Attribution License, which permits unrestricted use, distribution, and reproduction in any medium, provided the original work is properly cited.

\begin{abstract}
The purpose of this study was to optimize a composite method for the Geostationary Ocean Color Imager (GOCI), which is the first geostationary ocean color sensor in the world. Before interpreting the sensitivity of each composite with ground measurements, we evaluated the accuracy of bidirectional reflectance distribution function (BRDF) performance by comparing modeled surface reflectance from BRDF simulation with GOCI-measured surface reflectance according to composite period. The root mean square error values for modeled and measured surface reflectance showed reasonable accuracy for all of composite days since each BRDF composite period includes at least seven cloud-free angular sampling for all BRDF performances. Also, GOCI-BRDF-adjusted NDVIs with four different composite periods were compared with field-observation NDVI and we interpreted the sensitivity of temporal crop dynamics of GOCI-BRDF-adjusted NDVIs. The results showed that vegetation index seasonal profiles appeared similar to vegetation growth curves in both field observations from crop scans and GOCI normalized difference vegetation index (NDVI) data. Finally, we showed that a 12-day composite period was optimal in terms of BRDF simulation accuracy, surface coverage, and real-time sensitivity.
\end{abstract}

\section{Introduction}

Terrestrial products such as surface albedo and vegetation index play an important role in soil moisture and energy balance and are critical for understanding the boundary layer energy mechanism between the atmosphere and land surface $[1,2]$. Satellite imagery is considered an efficient tool for estimating terrestrial products, having the advantage of a worldwide spatial and temporal resolution. Surface vegetation conditions and dynamics in terrestrial products [3] have mostly been constructed from optical satellites such as the Advanced Very High Resolution Radiometer (AVHRR) [4], ModerateResolution Imaging Spectroradiometer (MODIS) [4-6], SPOT/VEGETATION [7], METEOSAT Second Generation (MSG) [8], Geostationary Operational Environmental Satellite (GOES) [9], and Medium Resolution Imaging Spectrometer (MERIS) [10]. Atmospheric effects and surface anisotropy scattering are the main obstacles to accurate estimates when using optical satellites to measure terrestrial products.
Although atmospheric correction models for the most common optical satellites are easily accessible using commercial remote sensing software, the bidirectional reflectance distribution function (BRDF) has a complicated methodology, which may restrict its utility among user groups. However, BRDF is a critical tool for reliably reducing the anisotropy associated with surface scattering effects, one of the main fluctuating error sources of relative solar-target-sensor geometry [11].

The most widely used semiempirical BRDF model for optical sensors is sensitive to the number of observations made under geometric conditions, and observations of a diversity of conditions have resulted in a higher quality BRDF product [12]. Sun- and Geosynchronous satellites have different angular sampling observations [13-15]. A typical MODIS among polar-orbiting satellites performs BRDF modeling using a 16-day composite period to provide a suitable tradeoff between the availability of sufficient angular sampling observations and the temporal stability of the surface $[16,17]$. 


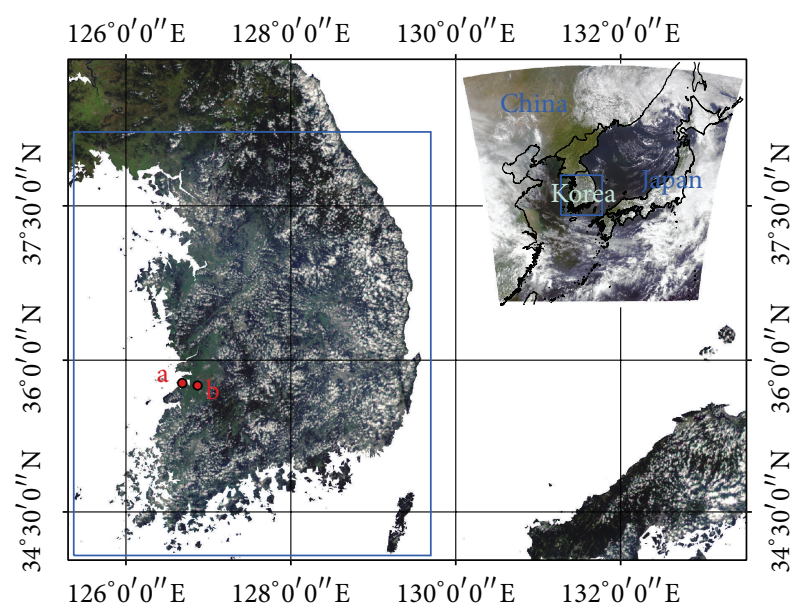

Figure 1: Geostationary Ocean Color Imager (GOCI) full disk image acquired on 11 September 2014, over Korea. The blue box marks the study area. Field-observation sites are denoted by red points (a: Kyehwa, b: Kimjae).

Geostationary satellites ensure repeatable sun illumination conditions during a given day, acquiring sufficient cloud-free surface reflectance to make a reliable BRDF model [18].

The Geostationary Ocean Color Imager (GOCI), the first geostationary optical ocean color sensor, has the potential to accurately estimate land surface products [19-22], because it provides images with high temporal resolution and has a spectral response function (SRF) over the solar spectral wavelength range, similar to MODIS sensors. SeaWiFs (SeaViewing Wide Field-of-View Sensor), another ocean color sensor, has previously been used for estimating terrestrial vegetation $[23,24]$.

It is impossible to obtain land surface spectral information under a cloudy area with optical satellite sensors, so composite days must be generated. The most commonly used 16-day composite for BRDF modeling in geostationary satellites $[20,25]$ shows reduced sensitivity to crop dynamics over selected rice paddy areas relative to real-time conditions. The sensitivity of BRDF models is reduced with longer composite days due to the additional time involved, despite adequate cloud-free sampling. Yeom and Kim [21], when comparing in situ Normalized Distribution Vegetation Index (NDVI) with GOCI-BRDF-adjusted NDVI, showed that the BRDF-adjusted NDVI profile was shifted relative to the in situ profile. These adjusted vegetation profiles are thus less sensitive to real-time change due to the composite period used for the BRDF model [21]. Therefore, it is critical to optimize the BRDF composite method for sensitivity to vegetation profiles, with a choice-adaptive composite period.

\section{Materials and Methods}

2.1. Study Area and Satellite Data. The study was conducted in the southern part of the Korean peninsula (Figure 1). The Korean peninsula is characterized by having four distinct seasons. The monsoon season, called Jang-Ma, brings considerable amounts of rain to the Korean peninsula in the
TABLE 1: Detailed characteristics of the Geostationary Ocean Color Imager (GOCI) and Moderate-Resolution Imaging Spectroradiometer (MODIS) sensors used for estimating land-surface products.

\begin{tabular}{|c|c|c|}
\hline Satellite & \multicolumn{2}{|c|}{ GOCI } \\
\hline Orbit type & \multicolumn{2}{|c|}{ Geosynchronous } \\
\hline Altitude & \multicolumn{2}{|c|}{$\approx 36,000 \mathrm{~km}$} \\
\hline Spatial resolution & \multicolumn{2}{|c|}{$500 \mathrm{~m}$ at nadir } \\
\hline \multirow{4}{*}{ Wavelength (nm) } & B1: $402-422$ & B5: $650-670$ \\
\hline & B2: $433-453$ & B6: $675-685$ \\
\hline & B3: $480-500$ & B7: 735-755 \\
\hline & B4: $545-565$ & B8: $845-885$ \\
\hline
\end{tabular}

summer between June and August, during which the Korean peninsula receives more than half of its annual precipitation. The annual mean temperature in South Korea ranges from 8.4 to $18.6^{\circ} \mathrm{C}$, except in the high mountain areas (Korea Meteorological Administration) [26].

The GOCI was launched successfully on 27 June 2010, with a $2500 \mathrm{~km} \times 2500 \mathrm{~km}$ field of view and eight multispectral bands, including visible to near-infrared bands. GOCI has a $500 \mathrm{~m}$ spatial resolution eight times a day, with a reobservation time of around 1 hour from 9 a.m. to 4 p.m. The characteristics of GOCI are presented in Table 1. We used bands 5 and 8 of NDVI, due to the similar spectral characteristics of these bands with respect to those of MODIS.

\subsection{Field Observation Using a Multispectral Radiometer} (MSR). Field measurements were obtained with a handheld portable CROPSCAN multispectral radiometer (MSR) to compare with satellite-based vegetation profiles. The MSR16 consists of 16 spectral bands over the wavelength range of $450-1750 \mathrm{~nm}$ and a measurement distance of $2 \mathrm{~m}$ from the sensor to the vegetation canopy. The MSR-16 measurements are unaffected by atmospheric conditions. To measure spectral information on rice paddies, we observed three different points within two sites under clear sky conditions (red points in Kyehwa and Kimjae, Figure 1) and then calculated the average of three points at each site (Figure 2). The instrument was operated during the growing season (13 June 2014, 26 June 2014, 15 July 2014, 22 July 2014, 11 August 2014, 26 August 2014, 15 September 2014, and 3 October 2014). Field observations were compared with satellite observation pixels to geometrically match observation points $(500 \times 500 \mathrm{~m})$.

\subsection{Preprocessing of Satellite Data and BRDF Modeling.} GOCI imagery was preprocessed before BRDF modeling. The preprocessing was included in converting the digital number to top-of-atmosphere (TOA) reflectance, cloud masking, and atmospheric correction. Cloud masking used a threshold method to reduce the probability of cloudy contamination [27]. An atmospheric correction model was applied to the TOA reflectance to estimate top-of-canopy reflectance using a look-up table based on the Second Simulation of the Satellite Signal in the Solar Spectrum [28-31].

To correct for surface anisotropy effects, we used the BRDF model developed by Roujean et al. [32]; in the 


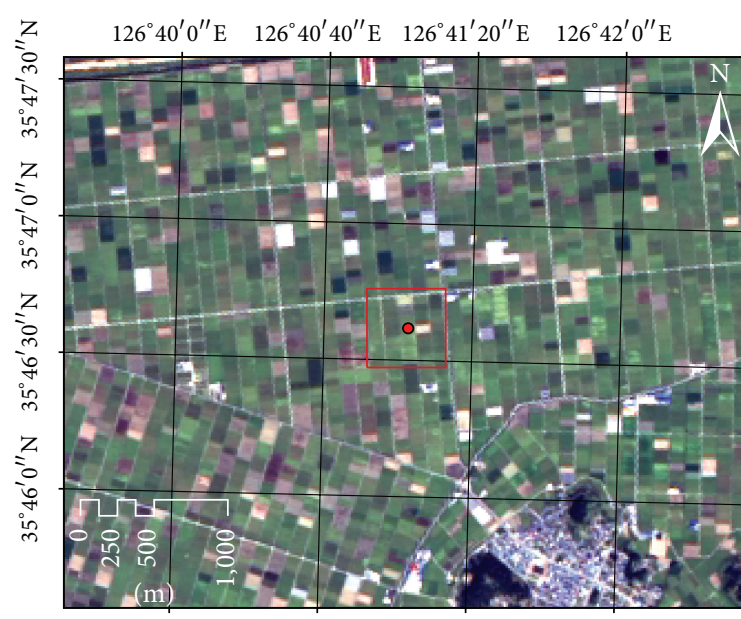

$126^{\circ} 40^{\prime} 0^{\prime \prime} \mathrm{E} \quad 126^{\circ} 40^{\prime} 40^{\prime \prime} \mathrm{E} \quad 126^{\circ} 41^{\prime} 20^{\prime \prime} \mathrm{E} \quad 126^{\circ} 42^{\prime} 0^{\prime \prime} \mathrm{E}$

(a)

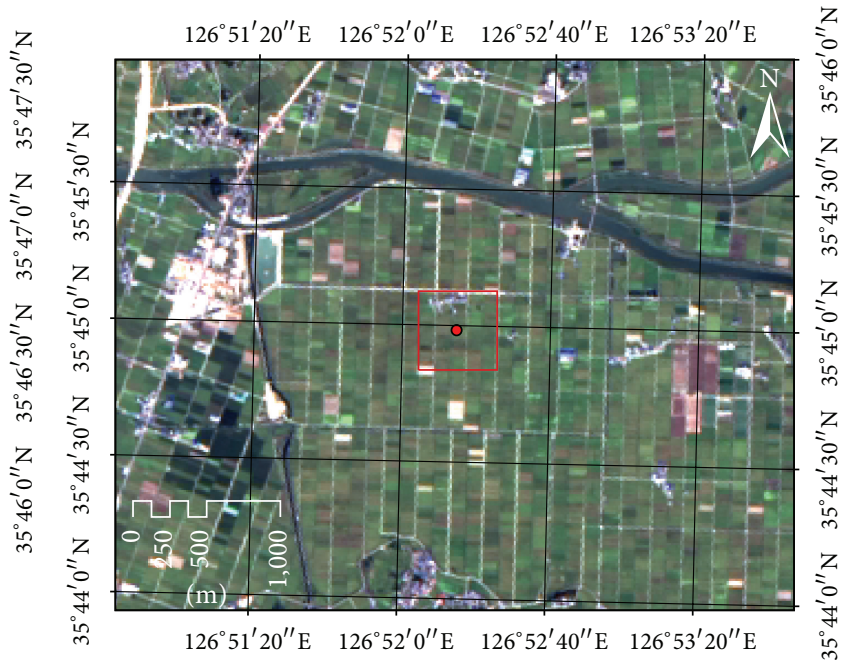

(b)

Figure 2: Detailed field-observation site images acquired on 5 October 2014, using the Landsat-8 operational land imager. The red dots are field-observation sites ( $\mathrm{a}$ and $\mathrm{b}$ from Figure 1), and the rectangles represent sites corresponding to one GOCI pixel.

semiempirical BRDF model proposed, there are three scattering components: isotropic scattering, geometric scattering, and volumetric scattering from a horizontally homogeneous vegetation canopy [33]. Consider the following:

$$
\rho\left(\theta_{s}, \theta_{v}, \emptyset\right)=k_{0}+k_{1} f_{1}\left(\theta_{s}, \theta_{v}, \emptyset\right)+k_{2} f_{2}\left(\theta_{s}, \theta_{v}, \emptyset\right),
$$

where $\rho$ is the observed reflectance in a given spectral channel, $\theta_{s}$ is the solar zenith angle (SZA), $\theta_{v}$ is the viewing zenith angle (VZA), $\emptyset$ is the relative azimuth angle (RAA), $k_{0}$ is isotropic coefficient of the Lambertian reflectance when $\theta_{s}=0$ and $\theta_{v}=0, k_{1}$ and $k_{2}$ are the empirical coefficients of the geometric and volumetric kernel, and $f_{1}$ and $f_{2}$ are physical geometric and volumetric scattering kernels depending on $\theta_{s}, \theta_{v}$, and $\emptyset$ between the sun and view direction of view. We applied our own fixed viewing angle and mean SZA during the composition period, without adjusting the VZA to the nadir direction based on Yeom and Kim [20].

Inadequate observation sampling leads to poor surface coverage, while long composite periods reduce BRDF model sensitivity to real-time vegetation change, even with adequate cloud-free observations. To improve the vegetation profiles estimated with BRDF composite methods, several composite periods were added to enhance the accuracy and sensitivity of BRDF modeling relative to ground measurements. Here, we used 4-, 8-, 12-, and 16-day composite periods for each pixel to determine the optimized GOCI-based, BRDFadjusted NDVI for each study area. Figure 3 shows the concept of alterative composite periods for BRDF modeling. To perform kernel-driven, semiempirical BRDF modeling, at least seven observations of clear free surface reflectance are required for reliable simulation results $[15,34]$. Finally, we estimated the daily NDVI product-based BRDF-adjusted surface reflectance (BAR).

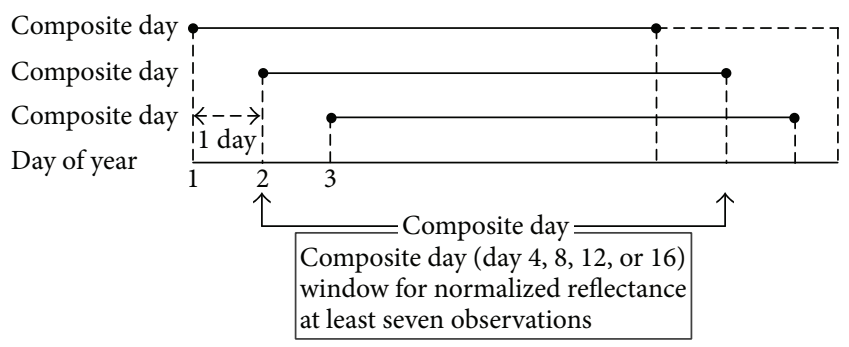

FIGURE 3: Concept of composite period for BRDF modeling.

\section{Result}

Before determining the optimized composite period of BRDF modeling, the accuracy of each composite period was assessed by simulating surface reflectance using BRDF coefficient parameters at the same sensor-target-sun geometry observations. Figure 4 shows the correlation between the measured channel surface reflectance of GOCI and the modeled reflectance from each of the BRDF composite periods. The results of modeled surface reflectance are shown in Figures 4(a)-4(d). Bands 5 and 8 have the lowest root mean square error (RMSE) values in all composite periods, which indicates that there was no difference in channel reflectance among the composite periods. The measured reflectance and modeled channel reflectance were not affected by composite period under clear sky conditions. We inferred that similar accuracy would be obtained for each BRDF composite period by including at least seven cloud-free angular sampling for all BRDF performances.

The GOCI BRDF-adjusted NDVI from each composite period was compared to assess the spatial coverage of all composite periods. Figure 5 shows sample data of GOCI BRDF-adjusted NDVI from different composite periods. The 


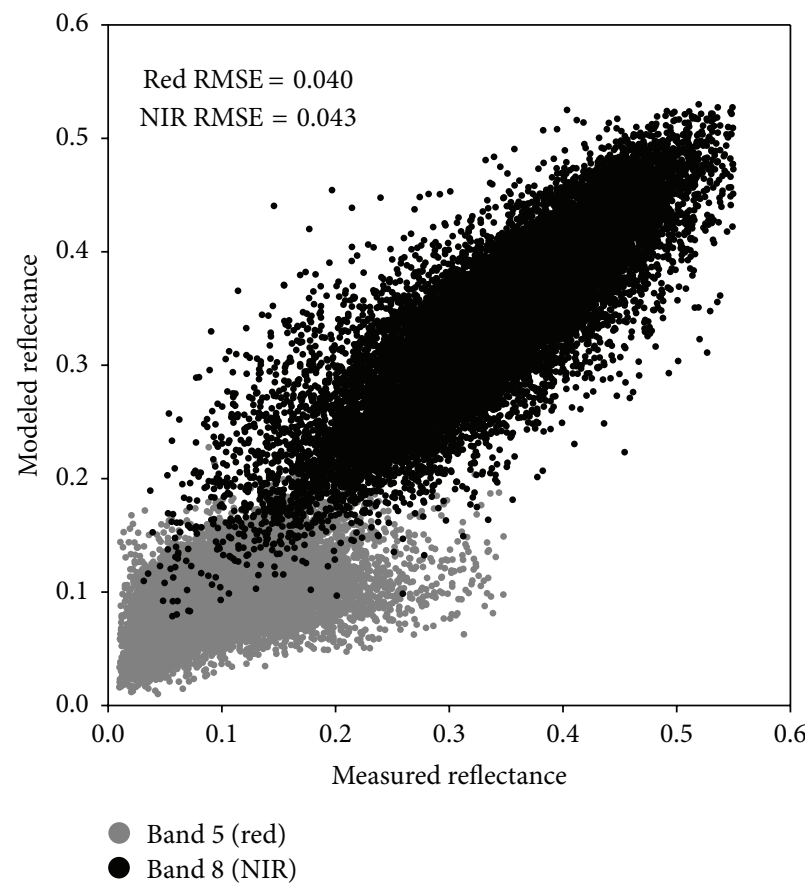

(a)

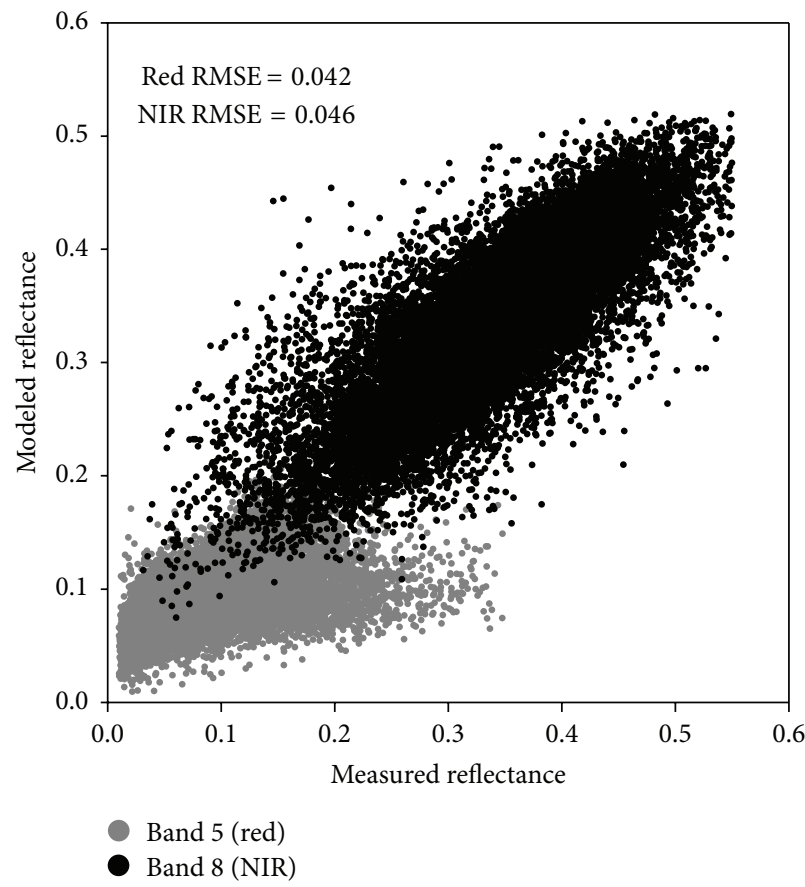

(c)

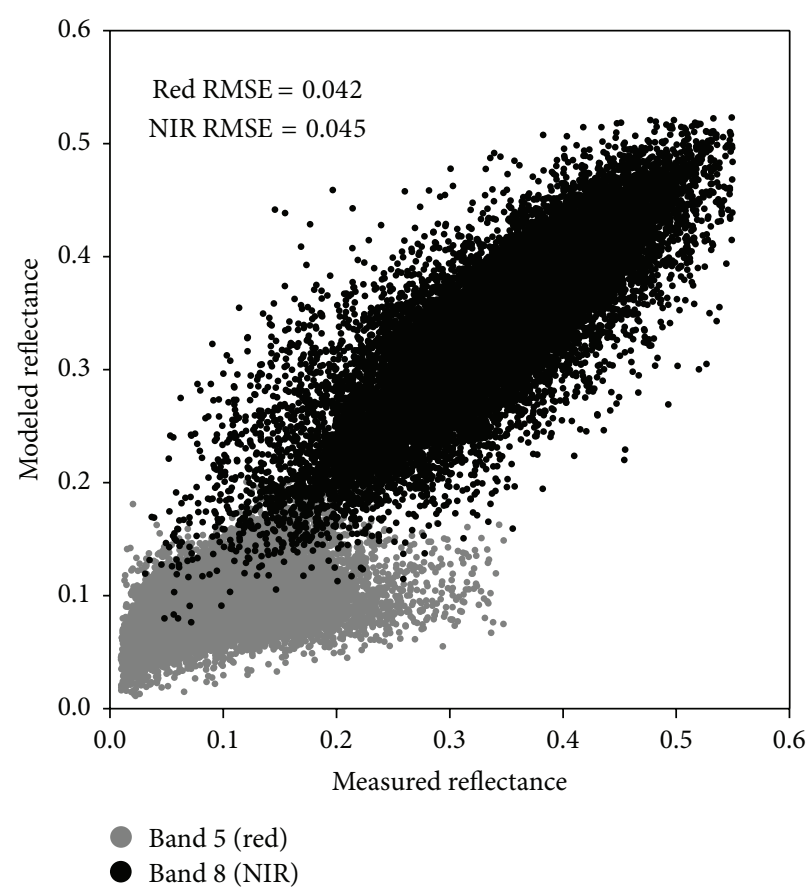

(b)

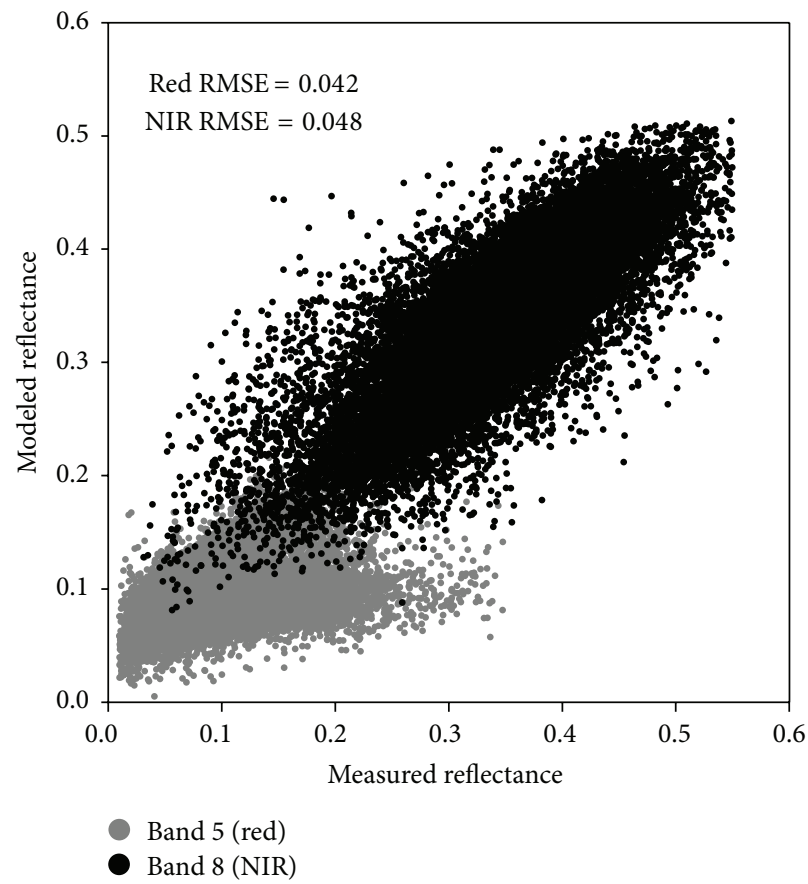

(d)

FiguRE 4: Scatterplots show the modeled channel reflectance versus measured channel reflectance for a (a) 4-day, (b) 8-day, (c) 12-day, and (d) 16-day composite period.

4-day composite period showed low coverage rate of usable surface reflectance pixels due to having a relatively low number of cloud-free observations (Figure 5(a)). The coverage increased with increasing composite period length due to the inclusion of more cloud-free measurements. The cloudy areas were nearly absent in Figures 5(c) and 5(d), due to adequate cloud-free sampling within the longer composite periods. In other words, longer composite days account for surface reflectance that would otherwise be obscured by cloud cover. However, longer composite days reduce sensitivity to changes in surface reflectance. Consequently, it is critical to identify an optimized BRDF composite period. 

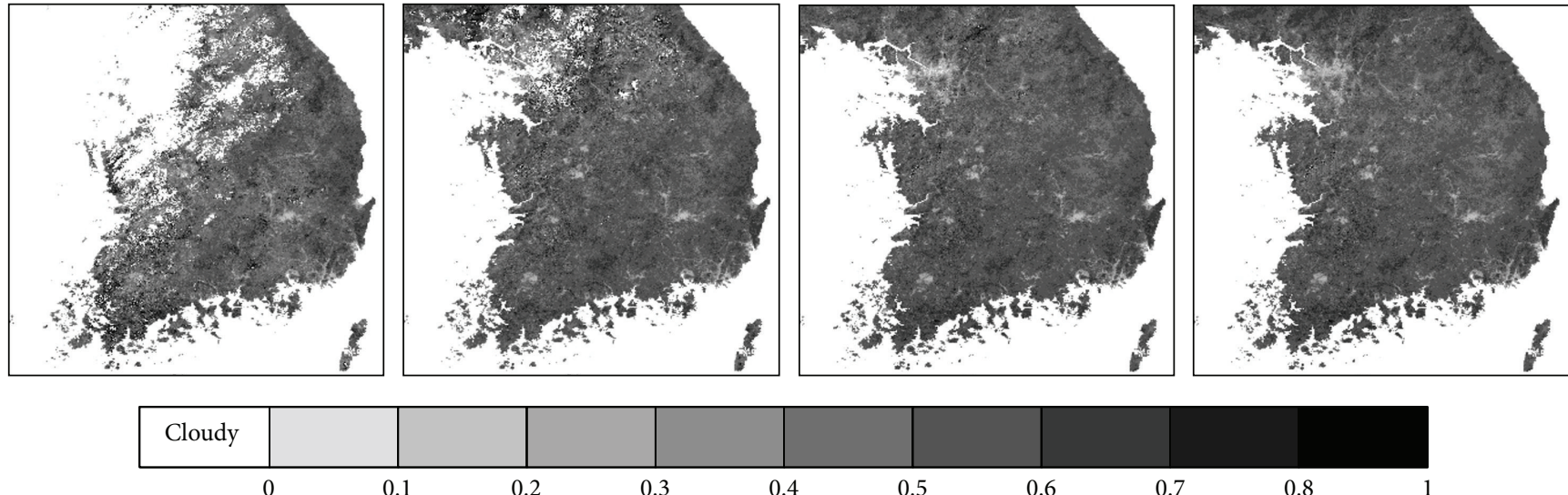

(a)

(b)

(c)

(d)

FIGURE 5: GOCI normalized difference vegetation index- (NDVI-) based bidirectional reflectance distribution function- (BRDF-) adjusted surface reflectance, by composite period (7 September 2014): (a) 4-day, (b) 8-day, (c) 12-day, and (d) 16-day composite period. White areas correspond to the ocean and cloud cover.

Figure 6 shows a comparison of GOCI NDVI-based BAR and field-observation NDVI from crop scans for the two crop sites; the measured NDVI is higher than the GOCI NDVI. This discrepancy could be explained by atmospheric correction and land cover types. The issue of atmospheric correction based on satellite data can be difficult to resolve. The field-measured NDVI value is observed directly at the rice paddy area, while GOCI NDVI includes many types of land cover, such as crops, roads, and structures, despite careful selection of the study sites. GOCI NDVI describes the general vegetation phenology pattern based on satellite data; the measured NDVI and GOCI NDVI have similar vegetation growth curves. Figure 6(a) shows the NDVI time seriesbased BRDF-adjusted surface reflectance at the Kyehwa site with late-maturing crops; Figure 6(b) shows the data for the Kimjae site with early-maturing crops. The BRDF-adjusted NDVI profile for all composite periods is sequentially shifted to the right compared with the vegetation growth curve of field-measured NDVI in both areas. BAR NDVI with 12-day and 16-day composite periods better followed the crop dynamics than the 4-day and 8-day composite periods. Therefore, the calculated BAR NDVI on 12-day and 16-day composite periods shows a stable crop profile. It is difficult to compare BAR NDVI and field-observation NDVI oneto-one, because heavy rain between Julian days 200 and 210 in June 2014 caused a sudden drop in BAR NDVI values. However, crop blooming during the field-observation periods appeared as maximum NDVI more quickly in the 12day composite period than in the 16-day composite period. BAR NDVI in the 12-day composite period was sensitive to real-time change in comparison with field-observation NDVI and provided reliable temporal crop dynamics.

\section{Conclusion}

This study estimated vegetation profiles using an optimized BRDF composite method. We ran our simulations using

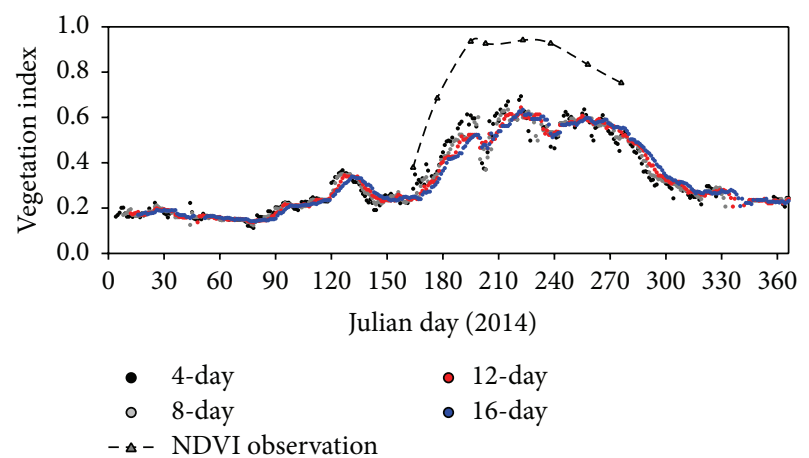

(a)

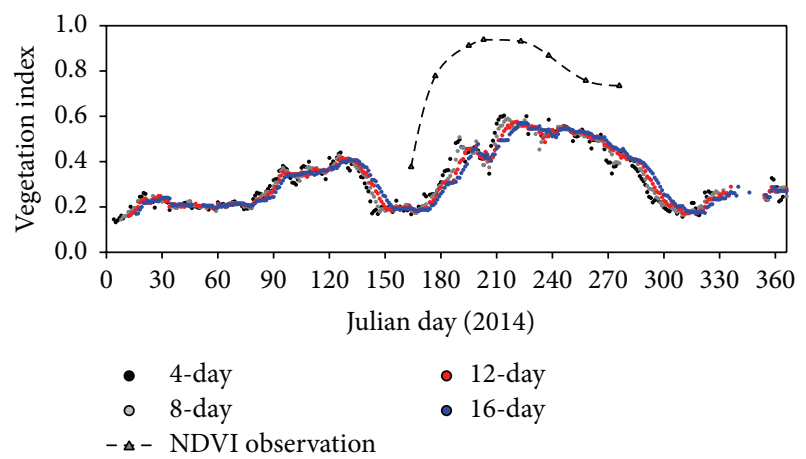

(b)

Figure 6: NDVI time series-based BRDF-adjusted surface reflectance at (a) the Kyehwa site and (b) the Kimjae site, by composite periods. The black, grey, red, and blue dots represent 4-day, 8-day, 12-day, and 16-day composite periods, respectively, and the solid line is the field-observation NDVI.

various composite periods and compared the NDVI profile derived from GOCI using four composite periods with field-observation NDVI. The BRDF composite method was tested with regard to modeling accuracy, spatial coverage, 
and sensitivity to real-time vegetation profiles. Finally, we determined that the 12-day composite period was both more sensitive to real-time vegetation changes and similar in terms of spatial coverage to the 16-day composite period. Although 4-day and 8-day composites were more sensitive to changes in ground measurements than the 12-day composite, they produced discontinuous vegetation profiles.

The optimized BRDF composite period identified in this study will improve the GOCI satellite's ability to measure realtime terrestrial products using the BRDF composite method.

\section{Conflict of Interests}

The authors declare that there is no conflict of interests regarding the publication of this paper.

\section{Acknowledgments}

This work was supported by "Development of Geostationary Meteorological Satellite Ground Segment" program funded by NMSC (National Meteorological Satellite Centre) of KMA (Korea Meteorological Administration).

\section{References}

[1] J. D. Tarpley, S. R. Schneider, and R. L. Money, "Global vegetation indices from the NOAA-7 meteorological satellite," Journal of Climate \& Applied Meteorology, vol. 23, no. 3, pp. 491494, 1984.

[2] C. O. Justice, J. R. G. Townshend, B. N. Holben, and C. J. Tucker, "Analysis of the phenology of global vegetation using meteorological satellite data," International Journal of Remote Sensing, vol. 6, no. 8, pp. 1271-1318, 1985.

[3] C. J. Tucker, "Red and photographic infrared linear combinations for monitoring vegetation," Remote Sensing of Environment, vol. 8, no. 2, pp. 127-150, 1979.

[4] R. B. Myneni, F. G. Hall, P. J. Sellers, and A. L. Marshak, "The interpretation of spectral vegetation indexes," IEEE Transactions on Geoscience and Remote Sensing, vol. 33, no. 2, pp. 481486, 1995.

[5] C. Justice, A. Belward, J. Morisette, P. Lewis, J. Privette, and F. Baret, "Developments in the 'validation' of satellite sensor products for the study of the land surface," International Journal of Remote Sensing, vol. 21, no. 17, pp. 3383-3390, 2000.

[6] A. Huete, K. Didan, T. Miura, E. P. Rodriguez, X. Gao, and L. G. Ferreira, "Overview of the radiometric and biophysical performance of the MODIS vegetation indices," Remote Sensing of Environment, vol. 83, no. 1-2, pp. 195-213, 2002.

[7] P. Maisongrande, B. Duchemin, and G. Dedieu, "VEGETATION/SPOT: an operational mission for the Earth monitoring; presentation of new standard products," International Journal of Remote Sensing, vol. 25, no. 1, pp. 9-14, 2004.

[8] R. Fensholt, I. Sandholt, S. Stisen, and C. Tucker, "Vegetation monitoring with the geostationary meteosat second generation seviri sensor," Remote Sensing of Environment, vol. 101, pp. 212229, 2006.

[9] Y. Tian, P. Romanov, Y. Yu, H. Xu, and D. Tarpley, "Analysis of vegetation index NDVI anisotropy to improve the accuracy of the GOES-R green vegetation fraction product," in Proceedings of the 30th IEEE International Geoscience and Remote Sensing
Symposium (IGARSS '10), pp. 2091-2094, Honolulu, Hawaii, USA, July 2010.

[10] J. Jin, H. Jiang, X. Zhang, and Y. Wang, "Characterizing spatialtemporal variations in Vegetation phenology over the NorthSouth transect of Northeast Asia based upon the MERIS terrestrial chlorophyll index," Terrestrial, Atmospheric and Oceanic Sciences, vol. 23, no. 4, pp. 413-424, 2012.

[11] S. Liang, A. H. Strahler, M. J. Barnsley et al., "Multiangle remote sensing: past, present and future," Remote Sensing Reviews, vol. 18, no. 2, pp. 83-102, 2000.

[12] S. R. Proud, Q. Zhang, C. Schaaf et al., "The normalization of surface anisotropy effects present in SEVIRI reflectances by using the MODIS BRDF method," IEEE Transactions on Geoscience and Remote Sensing, vol. 52, no. 10, pp. 6026-6039, 2014.

[13] F. E. Nicodemus, "Directional reflectance and emissivity of an opaque surface," Applied Optics, vol. 4, no. 7, pp. 767-773, 1965.

[14] M. J. Barnsley, A. H. Strahler, K. P. Morris, and J. P. Muller, "Sampling the surface bidirectional reflectance distribution function (BRDF): 1. Evaluation of current and future satellite sensors," Remote Sensing Reviews, vol. 8, no. 4, pp. 271-311, 1994.

[15] C. B. Schaaf, F. Gao, A. H. Strahler et al., "First operational BRDF, albedo nadir reflectance products from MODIS," Remote Sensing of Environment, vol. 83, no. 1-2, pp. 135-148, 2002.

[16] W. Wanner, A. H. Strahler, B. Hu et al., "Global retrieval of bidirectional reflectance and albedo over land from EOS MODIS and MISR data: theory and algorithm," Journal of Geophysical Research: Atmospheres, vol. 102, no. 14, pp. 1714317161, 1997.

[17] F. Gao, C. B. Schaaf, A. H. Strahler, and W. Lucht, "Using a multikernel least-variance approach to retrieve and evaluate albedo from limited bidirectional measurements," Remote Sensing of Environment, vol. 76, no. 1, pp. 57-66, 2001.

[18] W. Lucht and P. Lewis, “Theoretical noise sensitivity of BRDF and albedo retrieval from the EOS-MODIS and MISR sensors with respect to angular sampling," International Journal of Remote Sensing, vol. 21, no. 1, pp. 81-98, 2000.

[19] B. Uudus, K.-A. Park, K.-R. Kim, J. Kim, and J.-H. Ryu, “Diurnal variation of NDVI from an unprecedented high-resolution geostationary ocean colour satellite," Remote Sensing Letters, vol. 4, no. 7, pp. 639-647, 2013.

[20] J.-M. Yeom and H.-O. Kim, "Feasibility of using Geostationary Ocean Colour Imager (GOCI) data for land applications after atmospheric correction and bidirectional reflectance distribution function modelling," International Journal of Remote Sensing, vol. 34, no. 20, pp. 7329-7339, 2013.

[21] J. M. Yeom and H. O. Kim, "Comparison of NDVIs from GOCI and MODIS data towards improved assessment of crop Temporal dynamics in the case of paddy rice," Remote Sensing, vol. 7, no. 9, pp. 11326-11343, 2015.

[22] J. M. Yeom, J. G. Ko, and H. O. Kim, "Application of GOCIderived vegetation index profiles to estimation of paddy rice yield using the GRAMI rice model," Computers and Electronics in Agriculture, vol. 118, pp. 1-8, 2015.

[23] N. Gobron, F. Melin, B. Pinty, and M. M. Verstrasete, "SeaWiFS for global biosphere applications," in Proceedings of the IEEE International Geoscience and Remote Sensing Symposium, vol. 5, pp. 2238-2240, Sydney, Australia, July 2001.

[24] M. E. Brown, J. E. Prinzon, K. Didan, J. T. Morisette, and C. J. Tucker, "Evaluation of the consistency of long-term NDVI time series derived from AVHRR, SPOT-vegetation, SeaWiFS, 
MODIS, and Landsat ETM+ sensors," IEEE Transactions on Geoscience and Remote Sensing, vol. 44, no. 7, pp. 1787-1793, 2006.

[25] R. Fensholt, A. Anyamba, S. Huber et al., "Analysing the advantages of high temporal resolution geostationary msg seviri data compared to polar operational environmental satellite data for land surface monitoring in Africa," International Journal of Applied Earth Observation and Geoinformation, vol. 13, no. 5, pp. 721-729, 2011.

[26] Korea Meteorological Administration (KMA), Weather Almanac 2014, 2015.

[27] R. W. Saunders and K. T. Kriebel, "An improved method for detecting clear sky and cloudy radiances from AVHRR data," International Journal of Remote Sensing, vol. 9, no. 1, pp. 123150, 1988.

[28] E. F. Vermote, D. Tanré, J. L. Deuzé, M. Herman, and J.-J. Morcrette, "Second simulation of the satellite signal in the solar spectrum, 6S: an overview," IEEE Transactions on Geoscience and Remote Sensing, vol. 35, no. 3, pp. 675-686, 1997.

[29] M. Wang, "An efficient method for multiple radiative transfer computations and the lookup table generation," Journal of Quantitative Spectroscopy and Radiative Transfer, vol. 78, no. 34, pp. 471-480, 2003.

[30] A. S. L. Nunes, A. R. S. Marcal, and R. A. Vaughan, "Fast over-land atmospheric correction of visible and near-infrared satellite images," International Journal of Remote Sensing, vol. 29, no. 12, pp. 3523-3531, 2008.

[31] A. Lyapustin, J. Martonchik, Y. Wang, I. Laszlo, and S. Korkin, "Multiangle implementation of atmospheric correction (MAIAC): 1. Radiative transfer basis and look-up tables," Journal of Geophysical Research: Atmospheres, vol. 116, no. 3, Article ID D03210, 2011.

[32] J.-L. Roujean, M. Leroy, and P.-Y. Deschamps, "A bidirectional reflectance model of the Earth's surface for the correction of remote sensing data," Journal of Geophysical Research, vol. 97, no. 18, pp. 20-468, 1992.

[33] F. Gao, C. B. Schaaf, A. H. Strahler, Y. Jin, and X. Li, "Detecting vegetation structure using a kernel-based BRDF model," Remote Sensing of Environment, vol. 86, no. 2, pp. 198-205, 2003.

[34] W. Lucht, C. B. Schaaf, and A. H. Strahler, "An algorithm for the retrieval of albedo from space using semiempirical BRDF models," IEEE Transactions on Geoscience and Remote Sensing, vol. 38, no. 2, pp. 977-998, 2000. 


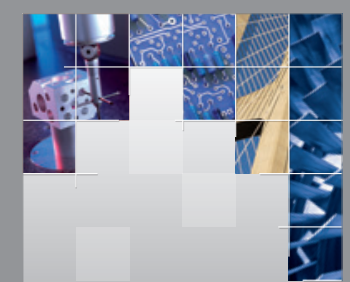

\section{Enfincering}
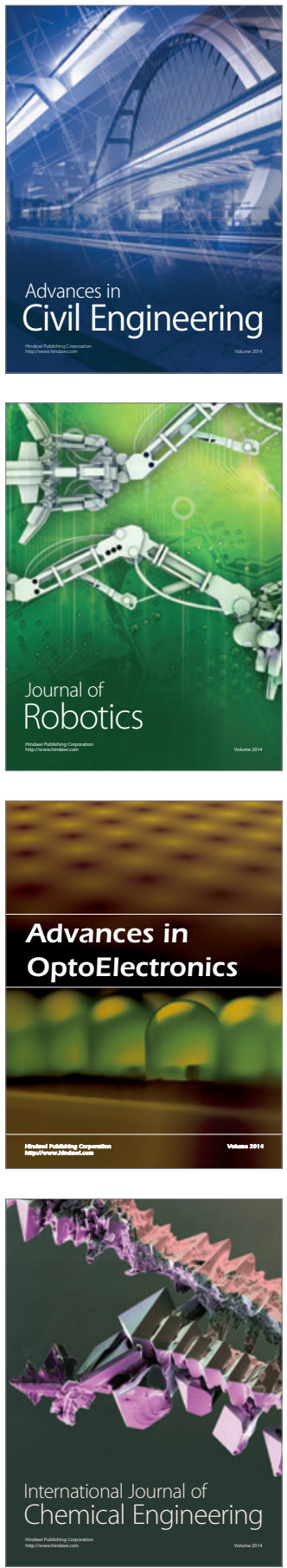

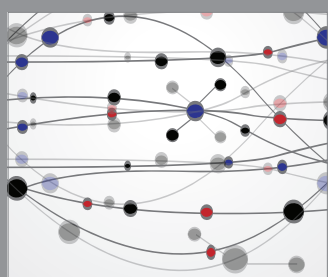

The Scientific World Journal

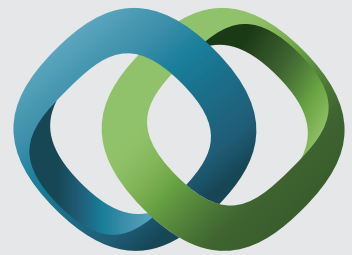

\section{Hindawi}

Submit your manuscripts at

http://www.hindawi.com
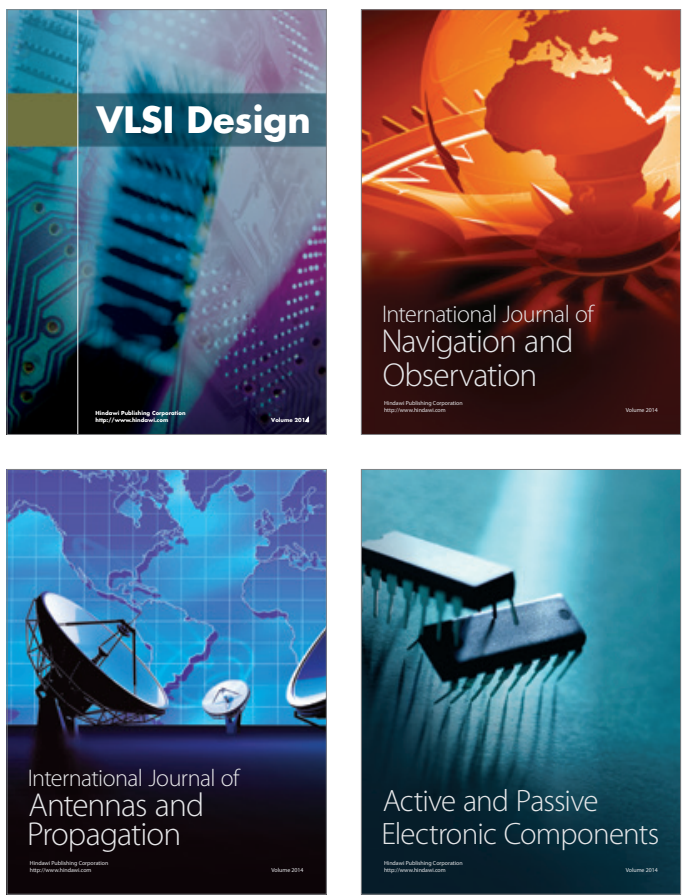
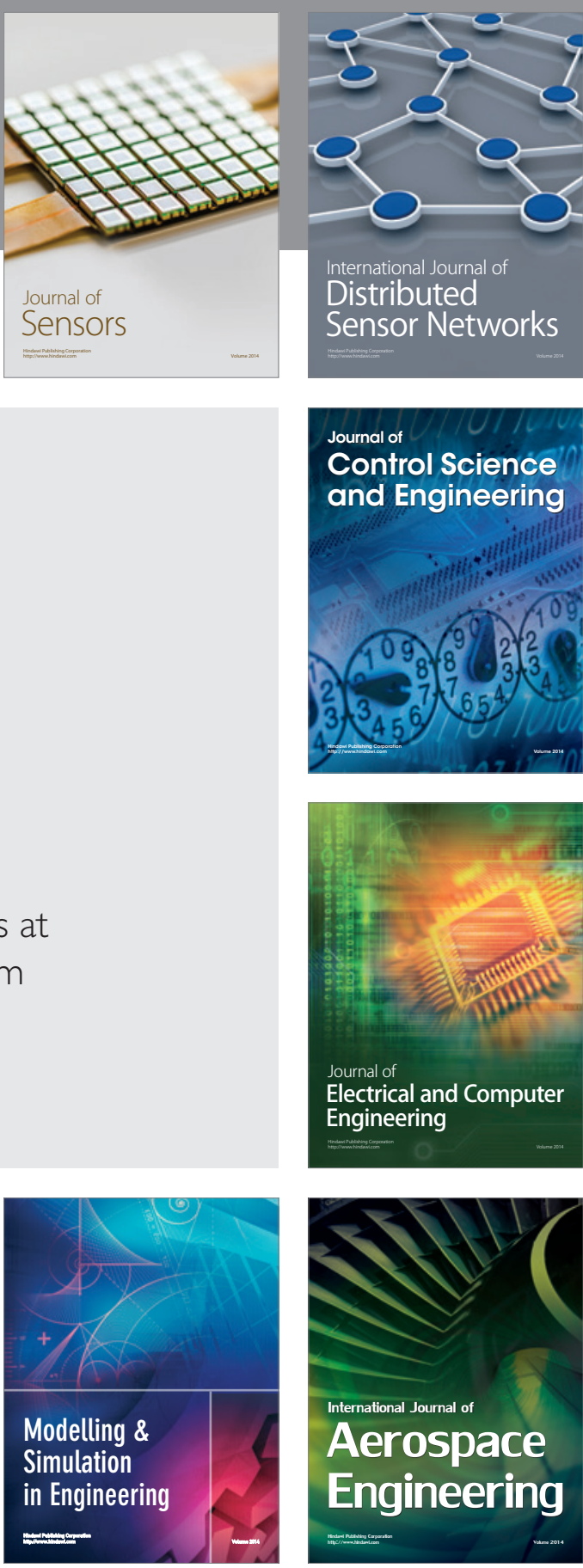

International Journal of

Distributed

Sensor Networks

Journal of

Control Science

and Engineering
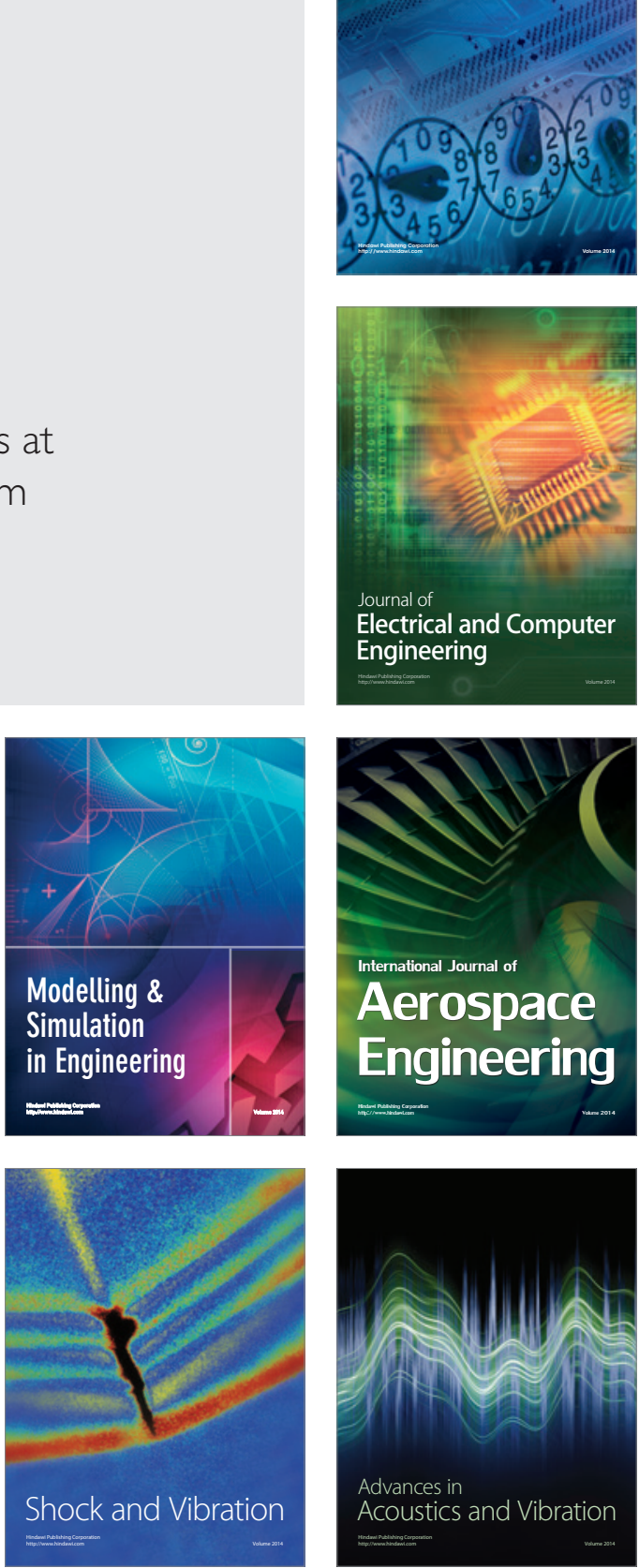